\title{
Bilayer melatonin tablet formulation: A novel approach to therapeutic efficacy
}

\author{
Herminia Castán Urbano, Ma Adolfina Ruiz Martínez*, Ma Teresa Sánchez Rodríguez, Elena Ortega Martínez y, Ma Encarnación Morales \\ Hernández
}

Department of Pharmacy and Pharmaceutical Technology, University of Granada, 18071 Granada, Spain

\begin{abstract}
Melatonin is a hormone with multiple actions, one of which, with proper administration, is the ability to control weight and prevent cardiovascular illnesses associated with obesity and diabetes. So, this work focuses on the design and creation of bilayer tablets which, through the top layer, permit a faster melatonin release after administration and, through the other layer, offer an extended release over time. The tablets are characterized from a technological perspective and have been subjected to disintegration and release tests to help determine their biopharmaceutical profile.
\end{abstract}

\section{Introduction}

Melatonin is a hormone that is found naturally in the organism in varying concentrations, depending on the diurnal/nocturnal cycle. It is mainly produced in the pineal gland and it participates in a wide variety of cellular, neuroendocrine and neurophysiological processes. One of its most noteworthy characteristics, with respect to the pineal biosynthesis of melatonin, is its variability over a 24hour cycle and its precise response to changes in environmental light. Depending on the dosage administered, its therapeutic effects differ; therefore, a relationship exists between dosage and therapeutic response. In fact, melatonin is used to treat insomnia, sleep disorders, neurodevelopmental disabilities, muscular dystrophy and as an alternative to the prophylactic preventive treatment of migraines [1]. Furthermore, Ahmad, et al. [2] revealed that the consumption of melatonin by obese diabetic rats helped to regulate their weight increase, stimulating the appearance of "beige fat", a type of fatty cells that burn calories instead of storing them, thus helping to control body weight. The levels of this "good fat" not only increased in the obese rats, but also in thin animals that were used as a control group. Therefore, with proper administration, MT may help control weight and prevent cardiovascular illnesses associated with obesity and diabetes [3].

The aim of this work is to produce bilayer melatonin tablets, made up of different components, that produce a fast-release and slow-release phase, in order to obtain a sequential release at different times, thus extending the therapeutic effect of the active ingredient [4]. Bilayer tablets are novel drug delivery systems [5] of increasing importance over recent years in the treatment of distinct diseases and in the production of different therapeutic actions [6]. In these systems, two or more drugs are compressed on top of one another to form a single unit. When two or more incompatible active ingredients are to be delivered, the creation of a bilayer tablet is the best option [7]. And for sustained release tablets, one layer is released immediately as an initial dose and a second layer provides the maintenance dose $[8,9]$.

The formulations under study were subjected to different technological trials to determine tablet dimensions and organoleptic characteristics, as well as the uniformity of mass, swelling capacity, hardness, disintegration and dissolution, in accordance with USP (United States Pharmacopeia) guidelines [10].

\section{Materials and methods}

\section{Materials}

Melatonin has been supplied by Methapharmaceutical IND SL (Barcelona, Spain). Ascorbic acid, Stearic acid, Lactose, sodiumCMC, Carbopol 934, Chitosan, Talc, Magnesium stearate, Sodium bicarbonate, Potassium carbonate, Magnesium stearate and all reagents used were purchased from Fagron Ibérica (Barcelona, Spain).

\section{Methods}

Tablets Design and Preparation: The formulation designed for a fast-release of melatonin contains a base with effervescent mixture to accelerate layer disintegration. Slow-release formulation contains retarding polymers, which assure a controlled melatonin release. Tablets were prepared by using a manual hydraulic press (SPECAC SC-15011, Spain) with a $13 \mathrm{~mm}$ diameter die on a single-punch and a compression force of 15 tons for $30 \mathrm{~s}$. Single-layer tablets were designed for slow- and fast-release formulation to study them on separately. Then a double-layer tablet was produced as final dosage form by layering in sequence both formulations (slow-, fast-release) in press matrix before compression.

Table 1 shows the components and amounts used to make the different layers of the tablet. The total dose of melatonin per tablet was $6 \mathrm{mg}$ ( $3 \mathrm{mg}$ of drug in each layer) and the total weight of the tablet was approximately $480 \mathrm{mg}$. We used different polymer concentrations during the slow phase to obtain tablets with the correct hardness (Table 1).

${ }^{*}$ Correspondence to: $\mathrm{M}^{\mathrm{a}}$ Adolfina Ruiz Martínez, Department of Pharmacy and Pharmaceutical Technology, Faculty of Pharmacy, University of Granada, 18071 Granada, Spain, E-mail: adolfina@ugr.es

Key words: melatonin, bilayer tablets, disintegration, dissolution

Received: June 16, 2020; Accepted: June 26, 2020; Published: June 29, 2020 
Table 1. Bilayer tablets formulation

\begin{tabular}{|l|c|}
\hline Slow-release layer & Formulation (mg) \\
\hline Melatonin & 13 \\
\hline Ascorbic acid & 10 \\
\hline Lactose & 60 \\
\hline Na-CMC & 150 \\
\hline Carbopol 934 & 30 \\
\hline Chitosan & 4 \\
\hline Talc & 1 \\
\hline Magnesium stearate & 271 \\
\hline compound weight slow-release layer & 3 \\
\hline Fast-release layer & 1 \\
\hline Melatonin & 100 \\
\hline Potasium carbonate & 60 \\
\hline Sodium bicarbonate & 40 \\
\hline Ascorbic acid & 5 \\
\hline Stearic acid & 209 \\
\hline Magnesium stearate & 480 \\
\hline compound weight fast-release layer & \\
\hline Total weight & \\
\hline
\end{tabular}

Technological Physical Characterization: Tablets were studied technologically [11] in terms of diameter, thickness, mass uniformity, and crushing strength Mass uniformity and crushing strength were analysed according to United States Pharmacopeia. Mass uniformity was evaluated using a precision balance (A\&D Europe $\mathrm{GmbH}$, Germany), data is reported as an average of 20 measurements \pm SD. Crushing strength was measured using a hardness tester (Pharm.Test, Germany), data shown is an average of 10 measurements \pm SD.

Swelling Study: In order to evaluate swelling capacity, expressed as hydration percentage, single-layer tablets constituted by matrix polymers were weighted $\left(\mathrm{W}_{1}\right)$ and placed into a pre-weighed stain less steel basket with 200-mesh aperture. Then, mesh containing each tablet was submerged into $25 \mathrm{~mL}$ simulated gastric fluid at $37 \pm 0.1^{\circ} \mathrm{C}$ in a glass beaker allowing tablets to swell. Baskets were removed from beakers and reweighed at predetermined times $\left(\mathrm{W}_{2}\right)$ after removing the excess water with a filter paper. The experiment was carried out in triplicate and the final data for swelling index (\%)

$$
\text { Swelling }(\%)=\left(\mathrm{W}_{2}-\mathrm{W}_{1}\right) \times 100 / \mathrm{W}_{2}
$$

Dosage Forms Disintegration: Disintegration assay was carried out according to USP 43. Double-layer tablets were studied in order to determined time of effervescency and time required for tablets disintegration. The experiment consisted of placing tablets on a perforated plate that allowed their contact with the medium $(800 \mathrm{~mL})$ at $37 \pm 0.1{ }^{\circ} \mathrm{C}$ and covered them in the top by a glass plate. The tablets will be found inside a "chamber" that would keep the moisture.

Disintegration assay is considered complete when:

- There is no residue on the grid.

- If there is residue, it is made up only of a soft mass that does not constitute a non-impregnated core.

- Only fragments of the tablet coating that adhere to the device remain on the grid.

In vitro melatonin Release Study: The release of melatonin from tablet was studied using the USP 43 dissolution apparatus II with a paddle speed of $100 \mathrm{rpm}$. Dissolution medium consisted of $500 \mathrm{~mL}$ gastric fluid ( $\mathrm{pH} 5.5$ ) at $37 \pm 0.1^{\circ} \mathrm{C}$. Melatonin released along $24 \mathrm{~h}$ was determined by spectrophotometry at $307 \mathrm{~nm}$ [12] at established times 1, 2, 4, 6, 8 y 24 hours. This plating procedure was carried out in triplicates. Previously, the melatonin assessment method was validated, being effective, precise and exact.

\section{Results and Discussion}

\section{Pharmaceutical Tablet Formulation}

Various polymer concentrations have been tested: chitosan, Carbopol $^{\circ}$ 934, and Na-CMC, but the one offering the best results is shown in Table 1. As shown in Table 1, slow-release layer formulations were examined, selected from previous pre-formulation work. For this, polymers (chitosan, $\mathrm{Carbopol}^{\circledR}$ 934, Na-CMC), which are capable of gelling in the presence of gastrointestinal fluids, were used and tested at different concentrations. Hydrophilic hydropolymers at moderate concentrations $(10-30 \% \mathrm{~m} / \mathrm{m})$ were used, forming a hydrophilic matrix. Upon entering into contact with water, these polymers experience rapid molecular hydration, forming a gel layer across the entire surface that controls the release of the active ingredient [13-15]. In this way, the slow release of melatonin is achieved using a hydrophilic matrix system. Although $\mathrm{Carbopol}^{\circ}$ has many advantages such as good mucoadhesive properties and a high gelling ability, it also has the disadvantage of being very sensitive to the medium's $\mathrm{pH}$, as mentioned above. Therefore, we considered the formation of an interpolymer complex (IPC) formed by the interaction of $\mathrm{Carbopol}^{\circ}$ and chitosan. The use of this IPC explains the slight variation in the $\mathrm{pH}$, solving the problem of Carbopol $^{\circledR} \mathrm{pH}$ dependence since its carboxyl groups are complexed with protonated amine groups of chitosan. Thus, there is a reduction in $\mathrm{pH}$-dependent drug release and a controlled release was possible.

On the other hand, the fast-release layer composition was the same for each formulation examined. So, double-layer tablets were obtained, with a final weight of $480 \mathrm{mg}$ (Figure 1).

\section{Technological Physical Characterization}

Once formulations were made via direct compression of the excipients, white bilayer tablets were obtained with no appreciable odor, a soft texture and smooth edges.

Tablets were technologically evaluated to determine diameter, thickness, mass uniformity and crushing strength [16,17]. In order to promote patient compliance, tablet diameter and thickness were carefully measured. Tablets were subjected to a hardness test and appropriate compactness and hardness were required in order to resist mechanical stress. Finally, the tablets offered a hardness of $38.33 \mathrm{~N}$,

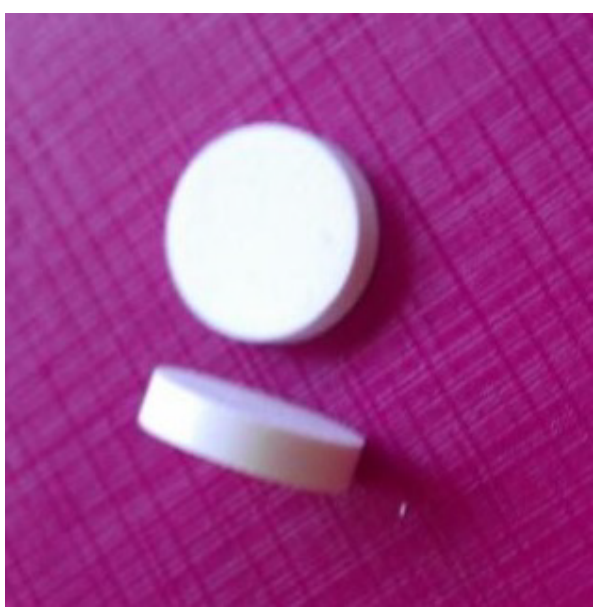

Figure 1. MT bilayer tablets 
offering them a high resistance during their handling throughout this study. According to the USP mass uniformity test, 20 tablets were weighted and mean weights were calculated at $480.9 \pm 5 \%$; no tablet had a deviation that exceeded $5 \%$ of the mean. Therefore, it is affirmed that this formulation meets all of the technological requirements.

\section{Swelling study}

Given the presence of swellable polymers in formulations, it was necessary to perform hydration studies in order to determine the tablet's swelling capability, which is directly involved in the gelling mechanism. Results for the formulation's water-absorbing capacity over time are presented in Figure 2.

It should be noted that once the optimum hydration point is reached, over hydrating leads to a decreased adhesive force, due to disentanglement at the polymer/tissue interface. This process may be divided into three main stages. The first is the moistening stage, taking place during the first 2 hours of the trial, since, when the hydrophilic matrix tablet comes into contact with water, the dry polymer is moistened until reaching its glass transition temperature.

It was observed (Figure 3 ) that 2 hours after immersion in the aqueous medium, the tablets had already begun to lose their initial form and were beginning to swell. This is considered the second stage, in which the polymeric matrix forms a gel layer, releasing the active ingredient. The ongoing entry of water into the matrix causes a progressive increase in thickness. During the first hour of the trial, the percentage of swelling exceeds 50\%, reaching $64.7 \%$ after two hours. And by 8 hours, the maximum hydration percentage is reached (76.5\%), with this value remaining until practically the end of the trial.

Similar results have been found by others authors [18,19], who have reported that these ratios for the chitosan/Carbopol ${ }^{\circ}$ interaction product stoichiometry suggest poor solubility properties. Furthermore, it is important to highlight the role of $\mathrm{Carbopol}^{\circ}$, given its high sensibility to the $\mathrm{pH}$ of the medium. According to other authors [20], the hydration and erosion level of the tablets was also found to be related and proportional to the Carbopol ${ }^{\circ}$ content.

\section{Disintegration}

Double-layer tablets were subjected to a disintegration assay. As expected, the disintegration time of the fast-release layer was less than $5 \mathrm{~min}$; specifically, it was 14 seconds. After 30 minutes, it was possible to see the formation of a gel on the surface of the matrix tablets. Two different parts were evident in these tablets: an external gelled layer and a non-hydrated inner zone containing polymers in a glassy state. When the matrix tablets were placed in contact with the medium, a diffusion/erosion front was created, enabling the release of melatonin into the medium. As the test progressed, it was possible to observe that this compact gelled layer gradually dissolved into a medium with no apparent fragment loss (Figure 3).

\section{In Vitro Release Study}

Finally, a dissolution trial was performed, once again, in accordance with the USP guidelines. After analyzing the results (Figures 4 and 5), it is seen that after 2 hours, a total of $2.3 \pm 0.6 \mathrm{mg}$ had been released. This was the result of the total melatonin release in the fast-release layer, which disintegrated in a few seconds (18 seconds). As revealed in the disintegration test, approximately $3.5 \mathrm{mg}$ remained in the tablets, released slowly in small amounts. At 8 hours, $4.28 \mathrm{mg}$ had been released. This release would continue progressively over 24 hours, when gel

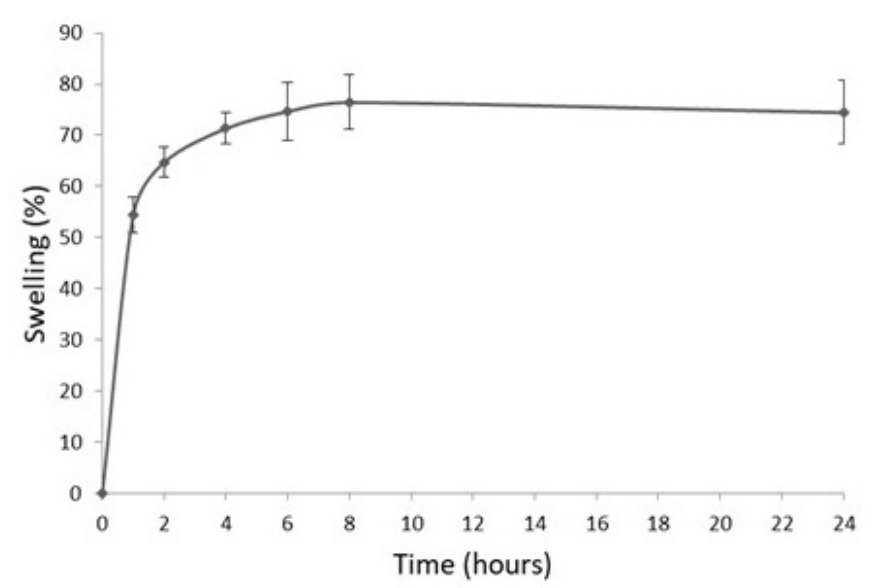

Figure 2. Swelling index (\%) of bilayer 1

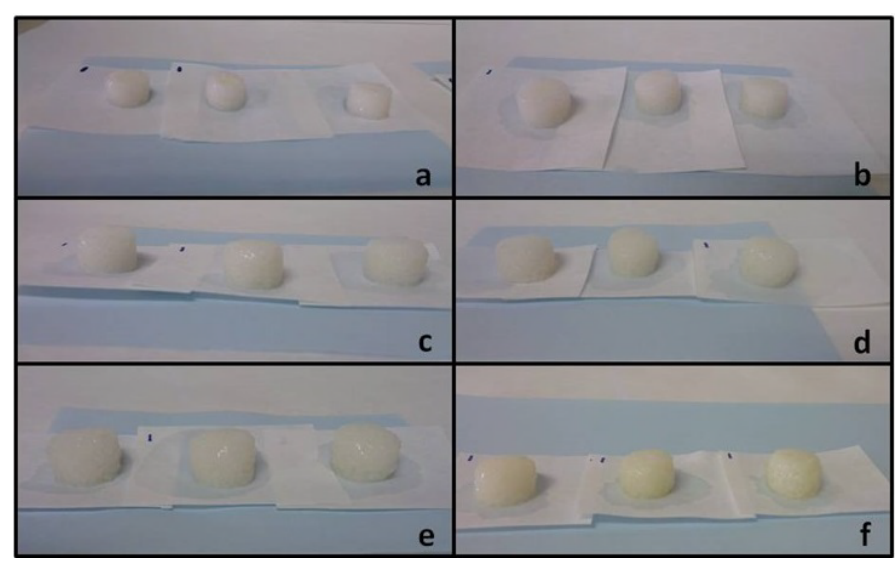

Figure 3. Images taken at 1 (a), 2 (b), 4 (c), 6 (d), 8 (e) and 24 (f) h of swelling study

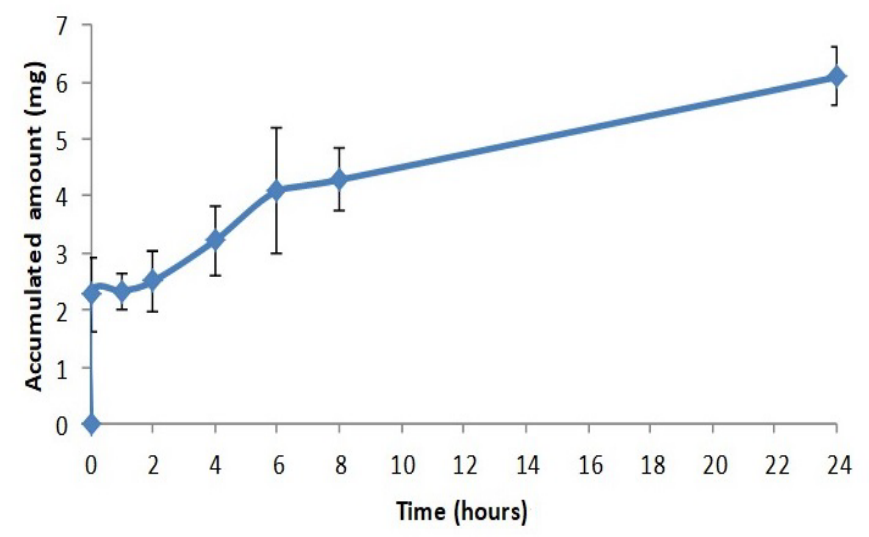

Figure 4. Release profile of melatonin tablet (accumulated amount of MT vs time)

residues were found to be fully depleted. Upon analyzing the results, a burst effect was seen at 2 hours, followed by a sustained release over 24 hours, at which point the proposed objectives had been reached.

So, with this fast release, approximately $38 \%$ of the active ingredient dosage was incorporated in this layer, with the release of the total tablet dosage being completed 24 hours after trial onset. However, the tablets did not fully dissolve (Figure 6), as corroborated by the results of the disintegration test, which resulted in a deformed mass with a gel-like appearance and fully depleted. 
Table 2. Tablets technological evaluation. Values are expressed as mean $\pm \mathrm{SD}$.

\begin{tabular}{|c|c|c|c|c|c|}
\hline Dimensions & Weight variation $(g) n=20$ & Friability & $\begin{array}{l}\text { Crushing Strength force } \\
(\text { Newton, } N) \mathrm{n}=10\end{array}$ & Disintegration & Dissolution \\
\hline \multirow{2}{*}{$\begin{array}{l}\phi=10,11 \mathrm{~mm} \\
\mathrm{~h}=4,53 \mathrm{~mm}\end{array}$} & \multirow{2}{*}{$\begin{array}{c}480.9 \mathrm{mg} \\
\pm 5 \% \\
(456.8-504.9 \mathrm{mg})\end{array}$} & \multirow{2}{*}{$2.36 \%$} & \multirow{2}{*}{$\begin{array}{c}38.33 \mathrm{~N} \\
\text { Máx: } 41 \mathrm{~N} \\
\text { Min: } 34 \mathrm{~N}\end{array}$} & Fast layer: 14 seg & $\begin{array}{c}\text { Fast-layer: } 17.7 \mathrm{sec} \\
2,3 \mathrm{mg}(38 \%)\end{array}$ \\
\hline & & & & Slow-layer: $24 \mathrm{~h}$ & $\begin{array}{l}\text { Slow-layer: } 24 \mathrm{~h} \\
6 \mathrm{mg}(100 \%)\end{array}$ \\
\hline
\end{tabular}

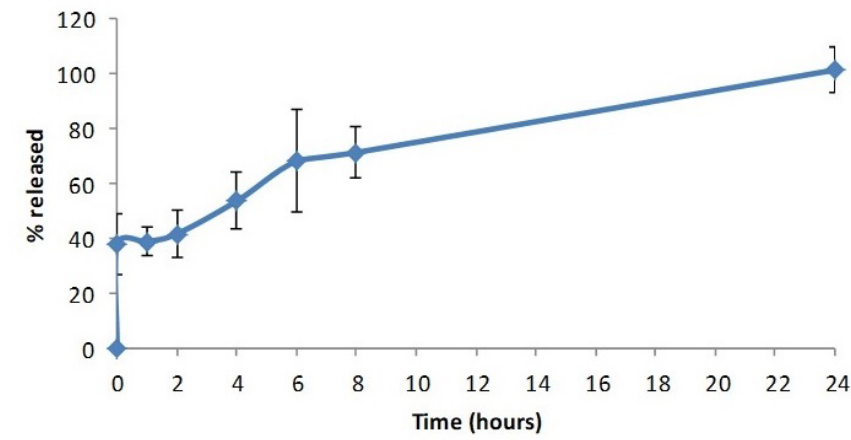

Figure 5. Dissolved percentage of melatonin as a function of time

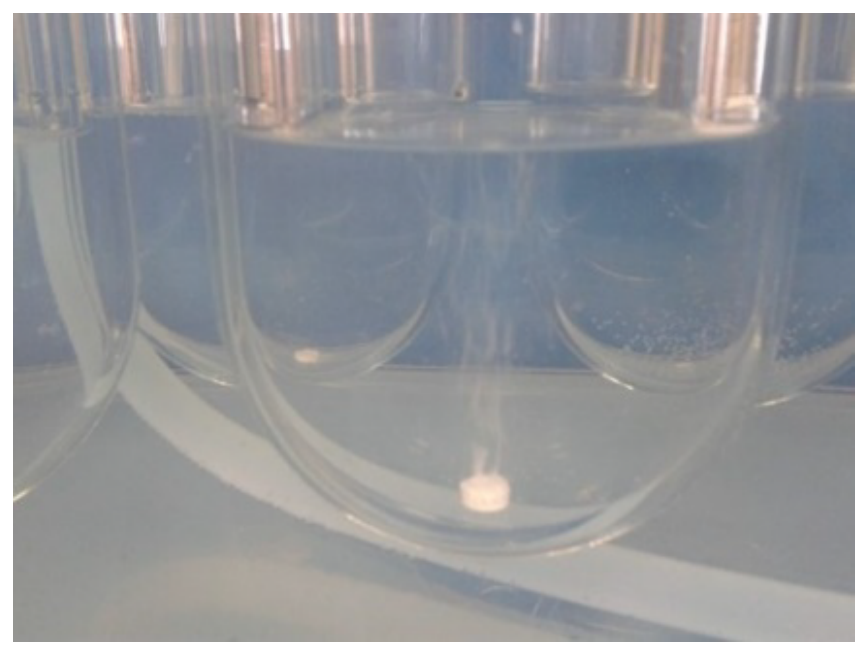

Figure 6. Effervescence of the tablet in the dissolution test

Finally, Table 2 offers a summary of all of the results obtained from the distinct trials performed on the solid, bilayer pharmaceutical form under study.

\section{Conclusions}

The results of this study suggest that the designed tablets offer ideal technological and pharmaceutical properties, making this a novel dosage form for effective and convenient weight control treatment in pathologies requiring a progressive release of melatonin.

Furthermore, a disintegration assay revealed that the effervescent layer disappeared in 14s, while the matrix layer was totally gelled in 1 $\mathrm{h}$. This gelled phase was homogeneous and progressively solubilized in melatonin with no fragment loss. A dissolution study confirmed two different release profiles based on the proposed tablet design: a prompt drug release during the effervescent layer and a prolonged release, extending over 24 hours, associated with the matrix layer.

\section{References}

1. Albertini B, Di Sabatino M, Melegari C, Passerini N (2014) Formulating SLMs as oral pulsatile system for potential delivery of melatonin to pediatric population. Int $J$ of Pharmaceutics 469: 67-79. [Crossref]
2. Ahmad (2018) Use of a melatonin agonist to induce beige adipocytes in white adipose tissue. Patent PCT/ES2018/070708.

3. Pattanayak DP, Dinda SC (2011) Bilayer tablet formulation of metformin $\mathrm{HCl}$ and glimepiride: A novel approach to improve therapeutic efficacy. Int J Drug Discov Herb Res 1: 1-4.

4. Abdul S, Poddar SS (2004) A flexible technology for modified release of drugs: Multi layered tablets. J Control Release 97: 393-405. [Crossref]

5. Kale SS, Saste VS, Prajkta L, Ughade, Dheeraj T, et al. (2011) Bilayer tablet: Review. Int J Pharm Sci Rev Res 9: 25-30.

6. Ramesh DS, Guruvaiah, Harani A (2010) Formulation and evaluation of bilayer sustained release matrix tablets of Metformin $\mathrm{HCl}$ and Pioglitazone. Amer-Euras $J$ Sci Res 5: 176-182.

7. Gopinath C, Himabindu V, Nischala M (2013) An overview on bilayered tablet technology. Journal of Global Trends in Pharmaceutical Sciences 4: 1077-1085.

8. Kumar GV, Babu KA, Ramasanay C (2011) Formulation and evaluation of bilayered tablets of cefixime trihydrate and dicloxacillin sodium. Int J PharmTech Res 3: 613618

9. Despande RD, Gowda DV (2011) Bilayer tablets-an emerging trade: a review International Journal of Pharmaceutical Science 2: 2534-2544.

10. USP 43-NF 38 (2020) The United States Pharmacopeia (USP) and the National Formulary (NF).

11. Musle K, Payghans A, Disuza JI (2011) Formulation, evaluation and development of bilayer tablet. Int J Pharm Res Dev 3: 80-87.

12. Ramirez MS, Castineira M, Nieto, OM (2009) Desarrollo de un método y su validación para la determinación de melatonina en tabletas. Superficies y Vacio 22: 29-32.

13. Jitendra R, Mohan A, Kalaskar G, Shrivastav VG, Yeole PG (2009) Bilayer tablet formulation of metformin hydrochloride and gliclazide: A novel approach in the treatment of diabetes. Int J Pharma Res Dev 1: 1-11. [Crossref]

14. Nirmal J, Saisivam S, Peddanna C, Muralidharan S, Godwinkumar S, et al. (2008) Bilayer tablets of atorvastatin calcium and nicotinic acid: Formulation and evaluation. Chem Pharm Bull 56: 1455-1458. [Crossref]

15. Kumar SS, Mohan S, Jaimini M, Tiwari R (2014) Polytherapeutic approach using bilayer matrix technology. Asian Journal of Pharmaceutics 4: 133-138.

16. Podczeck F, Drake KR, Newton JM, Haririan I (2006) The strength of bi-layered tablet. Eur J Pharm Sci 29: 361-366.

17. Ratnaparkhi MP, Vyas RG (2014) Bilayered Tablet Technology with Recent Advancement - A Review. Research. J Pharm and Tech 7: 1158-1164.

18. Rossi S, Sandri G, Ferrari F, Bonferoni M.C, Caramella C (2003) Development of films and matrices based on chitosan and polyacrilic acid for vaginal delivery of acyclovir. STP Pharma Science 13: 183-190.

19. Sánchez MT, Ruiz MA, Castán H, Morales ME (2018) A novel double-layer mucoadhesive tablet containing probiotic strain for vaginal administration: Design, development and technological evaluation. European Journal of Pharmaceutical Sciences 112: 63-70.

20. Perioli L, Ambrogi, V, Pagano C, Massetti E, Rossi C (2011) New solid mucoadhesive systems for benzydamine vaginal administration. Colloids Surf B Biointerfaces 84: 413-420. [Crossref]

Copyright: (C2020 Urbano HC. This is an open-access article distributed under the terms of the Creative Commons Attribution License, which permits unrestricted use, distribution, and reproduction in any medium, provided the original author and source are credited. 